\title{
Another fine mess? Which theory for which English?
}

David N. Brown

\section{OpenEdition}

\section{Journals}

Electronic version

URL: http://journals.openedition.org/asp/4361

DOI: $10.4000 /$ asp.4361

ISSN: 2108-6354

\section{Publisher}

Groupe d'étude et de recherche en anglais de spécialité

\section{Printed version}

Date of publication: 1 March 1993

Number of pages: 63-71

ISSN: 1246-8185

\section{Electronic reference}

David N. Brown, « Another fine mess? Which theory for which English? », ASp [Online], 1 | 1993, Online since 23 April 2014, connection on 20 April 2019. URL : http://journals.openedition.org/asp/4361 DOI : 10.4000/asp.4361

This text was automatically generated on 20 April 2019

Tous droits réservés 


\title{
Another fine mess? Which theory for which English?
}

\author{
David N. Brown
}

Language learning theory is in a state of disarray. This has always been the case. Progress in approaches and techniques has been made on a step by step basis and teachers have found themselves struggling - doing their best to do their best. But lack of a general theory is not necessarily a negative situation for from it has come a diversity of methodologies which guarantee variety and cater for the majority of teaching/learning environments. Furthermore, one might wonder if a general theory is indeed possible for a creature as complex as the humankind. But even if there is no general theory, over the past decade or so, an all-encompassing methodology has come to the forefront. This methodology is referred to as the communicative approach. Most teaching today, even when it is vaguely reminiscent of past practices, is associated to this methodology. So, today's communicative approach more fully integrates other approaches than when it was in its infancy. This I call the global approach.

Within this hotchpotch where just about everything overlaps, is there room for a newcomer, namely an approach that bases teaching material in LSP on specialist competence? Or is the newcomer merely something old, something we've already got, dressed up as new? Indeed, if too many cooks can spoil the broth, can too many ingredients have a similar effect?

3 It is no longer reasonable to single out a particular language-learning methodology, raise it up on a pedestal, and pin a medal on its chest with the inscription: "here stands the ultimate in language learning philosophies." The last methodology to really make an impact within the field of foreign-language learning was the communicative approach. This, I think it is safe to say, brought about a revolution in language learning. Today, there is little hope of contributing anything to language learning that would have the same impact as that earlier upheaval. But there may be just one exception. It thus seems inevitable that there should have evolved, rather than totally new approaches, methodologies corresponding both to the various specialist languages being taught and to 
the concomitant constraints that appear within the many teaching environments that exist. However, it seems clear that the framework for any step forward is invariably the communicative approach and it is only from this point of view that we can evaluate any newcomer to the realms of language-teaching methodology.

Taken in a broad sense - that is to say, as the progressive improvement of our (and by "our" I mean the community of language teachers as a whole) comprehension of how language is learned -the intellectual enterprise of language research, or more broadly speaking applied linguistics, came of age, in my opinion at least, really only just after the Second World War. The maturing experience was directly or indirectly due to US Air Force use of tape recorders in foreign language training. The idea took a decade and a half to crystallize, but by the 60 's the language-laboratory era had been launched.

5 This was the turning point. Before language labs, language teaching had been in the Dark Ages. I wasn't around then, but from what I'm told language teaching implied bizarre, even uncanny practices like chalk and talk, grammar, translation or even drilling.

It doesn't bear thinking of, does it? But the learning of languages as part of human endeavour was a going concern - by that I mean that languages got learned so those approaches had some success. Well, the audio-active approach - viz, the language lab gradually put an end to all of that and teaching somehow found itself in the "behaviourist-structuralist" era. But what does this mean? The structuralist bit is easy: in a lab the student would listen, record, compare and, possibly, repeat. Listen to, record, compare and repeat what? No prizes for getting the right answer - lists of identical, at least as far as their syntactic structure is concerned, sentences. Wait a minute. Do you mean the repeating of sentences with similar grammatical features? Yes. That's drilling, isn't it. Eh, yes. So, we're back in the Middle Ages. No, because it's all done orally with the student working at her own speed in her own private booth. So, what we've got is an individualized, self-teaching process. oh, good I was worried back there for a moment.

7 But what about behaviourism? Well, apparently if you get an animal - the human being is an animal, language learners are human beings and, therefore, are animals also - to carry out the same action often enough, it will end up by being conditioned to do the action as a mechanical reflex. This explains why so many learners make atrocious errors - they pick them up for their teachers, obviously.

What came next? Audio-visual. Stills, slides, with video as a rear guard and, of course, a sound track. At the same time there were role-play, simulations, pair-work, the functional approach. Detailed listening, global listening. More specifically in LSP we had the concept-based syllabus, on the one hand, and the rhetorical-functional syllabus, on the other hand, in which Widdowson slipped back into behaviourism. Somewhere in there the grammar-no-go philosophy appeared, as well as the L2-acquisition-equals-L1acquisition theory.

9 There were also error analysis, auto-correction and contrastive analysis, the latter putting the burden of proficiency in the learner's mother tongue on her teachers. Later, autonomy came along; the accent was shifted from teaching to learning; CALL turned up on the scene. And all throughout, the idea that the communicative approach as the only all-encompassing philosophy became clearer and clearer.

10 All of the above systems, or approaches, although generally considered unique in themselves, do tend to possess rather fuzzy boundaries, but when a particular technique or method is categorized the choice to place it within one or the other approach tends to 
be still somewhat arbitrary. It is not easy, for example, to differentiate with certitude between errors due to the phenomenon known as over-learning and those due to L1 interference, or to separate clearly the arguments used in the debate about language acquisition in which, on the one hand, the learner sets out to acquire language as a set of pre-described rules (this is bringing us back to the structuralist era) or, on the other hand, she (re-)creates the language which is then a function of her personal, theoretical construct. In a nutshell, her idiosyncratic dialecta; hence, errors are explained. Here, we are only a short step away from Kant and Piaget who claim that all knowledge bears the imprint of the mind's own structure. Piaget even refers to "genetic epistemology." So even philosophy gets in on the act.

11 This diversity of concerns and approaches has affected the relationships between language-acquisition theory and other neighbouring disciplines. On a practical plane, for instance, different theoretical interpretations have implied different procedures for testing and assessing the strength of rival concepts and hypotheses. Thus, no clear dividing line can be drawn between the linguistic analysis of pragmatic errors and the anthropological analysis of social behaviour. Furthermore, it seems clear that the particular questions raised by the linguist in her analyses inescapably depend on her attitudes and commitments to the methodology, approach or concern at hand.

Now, what has this rapid survey got to do with the current question - language-learning material as a function of specialist competence. Well, first of all, it is not an effort to prejudge that issue, whether the concept is legitimate or whether it already exists in another form, overlapping into well-know concepts that are referred to under other names. What it attempts to do is to place the debate in context by looking at what we already have to go on. Also, it has been a reminder, I hope, that in spite of the great flux and reflux that has been present in language teaching or learning approaches for the past few decades, the ideal approach has not yet been elaborated. Indeed, one wonders if such an approach can be brought into existence. The reason is simple, and two-fold.

In the first place, not unlike fashion in the rag trade, approaches that were thought to be obsolete have made their way back into the classroom. A colleague of mine, when I asked her if the centre she runs was equipped with a language lab, replied: "Language labs are out. Didn't you know?" Of course I did. But what do you de when you require twenty students to prepare oral presentations on classroom time? Preparation of an oral presentation requires, logically, oral practice with, preferably, the option of hearing oneself as others do. A language lab, or some other similar facility, seems ideal. of course, the use it is put to isn't quite the same as in the past. Grammar and translation, the terrible twins orphaned by the communicative approach, have slowly infiltrated back into the classroom. One major criticism of certain CALL software is the fact that it is merely on-screen, electronic drilling. This state of affairs is typical, for in any scientific system there are always permanent structures and relationships behind the evident flux of phenomena, especially the one known as fashion. Perhaps these are the permanent structures, the ones needed by learners for whatever the reason.

In addition, current classroom use of the computer is to language-learning techniques what the first automobile was to the horse-drawn carriage. When the automobile first appeared it was referred to as a "horseless carriage". It was seen merely as a continuation of an old technology with unchanged uses, rather than a totally new technology that opened up new possibilities. The machine was even built to resemble the carriages of old. It took decades for people to realize the potentials of this new machine. Similarly, 
language-learning software has had very little to offer in the way of novel techniques. Only of late has software based on totally different concepts leading to totally new approaches started to appear. Unfortunately, the language specialist deserves little or no credit for this.

Finally, is it not the destiny of any revolution, this is how I referred to the communicative approach a little earlier on, to turn full circle and end up back where it started? This is perhaps the simplest explanation for recurring trends. Of course, fundamentalists of the various approaches have survived. They vehemently exclude those terrible twins from their classroom, while others reject using the target language in comprehension exercises, and even a few totally exclude classrooms claiming that autonomous learning is the only possible way to enlightenment.

On the other hand, no approach is suited to all the members of a given language-learning community. To claim so would be ethnocentric to say the least and demonstrative of a rather poor understanding of human nature, and more precisely language learners' needs. In any case, even if there is one ideal approach, its worth has yet to be proved scientifically.

17 So, what have we got? Well, to borrow the words from a hit song that made the charts before I was born, "a great, big melting pot." All of the approaches are in there simmering away, slowly merging into a uniform pulp. From time to time one of them gets churned to the top and every body gets excited about it. This is what I call the global approach and it basically involves simply extracting what is needed from the melting pot in order to respond to the particular needs of a particular learning community at a particular moment in evolution. It can be communicative with or without grammar, totally or partially self-directed, grammar, translation or anything else.

In such an approach, how can a new concept fit in? To find out if it really can fit in, it is necessary to find the answers to a certain number of fundamental questions:

- Is its efficiency scientifically verifiable?

- What theory of learning is it based on and how will it affect the learning process?

- Is it born of empirical experience or hypothesis?

- Is it because of a deficiency in current approaches or instead of current approaches, i.e., an alternative approach.

- Will it give us a teaching-learning aid we do not already have?

- Is it adaptable (to all LSP situations, to all learning environments, to all cultural environments)?

- Is there a theoretical construct?

- What exactly will it contribute to the global approach?

- Does it rival something already existing?

19 But in spite of these questions and whatever the answers to them may be, there does seem to be some sense in ESP content as a function of specialist competence:

Given that university students of science and engineering will already be familiar in their first language with how scientific communication is carried out, it follows that the EST teacher's task is to provide an alternative and English way of communicating the knowledge of science they already have, and to provide access to texts written in English but structursd in terms of communicative units with which they are also familiar (Swales 1988: 70). 
21 Although by referring exclusively to written texts Swales (1988) unwittingly excludes other media of communication, and assuming that the student does indeed possess a knowledge of science, and familiarity with how scientific communication is carried out in her own language, the latter being by no means certain, what better technique for making the learner aware of the scientific characteristics of the language she is learning than via the vector of authentic scientific material whether this involves speaking, writing, listening or reading. However, what must be avoided at all costs is bogging the student down in scientific data she cannot handle. This would inevitably bring about a switch from the carrier, the language and its structure, to the cargo, the information and it implications. A rule of thumb is, if the teacher understands then the students will too.

Nevertheless, the above does not take into account any of the peripheral problems that can frequently upset such a pedagogical standpoint. What of absolute beginners in language who have $\mathrm{PhD}$ 's in outlandish and extremely specialized topics like "Memory Alloys and the Spoon-Bending Phenomenon"? What about relatively proficient learners who are only starting their scientific syllabus? What about the availability of authentic material? What about learner motivation? What about class sizes? What about the ethnocultural origins of the learners that may preclude learning via one means or another? Should we be teaching the highly specialized jargon used by some specialists in their fields? Can this approach be used when the accent is being laid not only on the acquisition of technical English, for example, but also on the mastering of paralinguistic skills like note-taking or oral expression techniques.

All of these questions might bring to mind arguments for or against the proposed approach, and which disfavour or support a global approach. The global approach in itself is a pretty muddled hotchpotch of ingredients. It is not really rule-governed, it has no theory and the nearest thing to a philosophy is that one does for the best according to constraints.

That exception which I mentioned earlier is, of course, CALL. There is every reason to expect, to even hope, that learning as it is today will disappear. Totally computeroriented approaches, techniques and methodologies that only the computer can offer will appear. These will take much of the sweat out of the learning process. They will also eliminate the possibility of teaching erroneous information. They might standardize languages, moulding them, to the dismay of some, so that accents and local dialects will eventually fade. The teacher may become a historical curiosity, hauled out, like horsedrawn vehicles, on celebration days for parades. Or perhaps this scenario is taking things too far.

But whatever the future holds for us, there can be no harm in adding another ingredient to the pot as long as we remember that there's little use in pouring in courgettes when there's already zucchinis in there. The contents of our linguistic cauldron is at present in disorder, can the mess be cleaned up; indeed, is there any point in trying? 


\section{BIBLIOGRAPHY}

Coder, S.P. 1974. "Idiosyncratic dialects and error analysis". In Richards, J.C., Error Analysis. London: Longman.

Swales, J. 1988. Episodes in ESP. London: Prentice Hall.

\section{AUTHOR}

\section{DAVID N. BROWN}

École supérieure des sciences et technologies de l'ingénieur de Nancy, Université de Nancy 1 (ESSTIN) \& CUCES-Universités (Centre universitaire de Co-opération économique et sociale). david.brown@esstin.uhp-nancy.fr 